\title{
Analytical estimation of diametral error in turning process considering flexible supports
}

\author{
Kalidasan Rathinam*, Sandeep Kumar, and Vivek Sharma \\ School of Mechanical Engineering, Lovely Professional University, India
}

\begin{abstract}
Turning is a fundamental metal cutting process. Diametral accuracy plays a vital role while turning long and slender workpieces. Hence the estimation of diametral error becomes more important for work pieces generally with slenderness ratio greater than six. The diametral error during the turning process is caused mainly by radial cutting force component and tangential cutting force component. Apart from this, it is also affected by cutting conditions, rigidity of the machine tool and type of support condition of the work piece. The main aim of the present research work is to construct an analytical model of turning process and to estimate the diametral error of the work piece. The cutting tool edge deflection is determined based on Euler Bernoulli beam theory. The work piece is considered as propped cantilever beam with flexible supports at the ends. These flexible supports are introduced taking the rigidity of head stock and tail stock into consideration. The radial deflection of the work piece is estimated for different slenderness ratio. It was found that the diametral error was lesser near the head stock end when compared to the tail stock end. This is due to the fact that the rigidity of the head stock higher than the tail stock. The maximum diametral error was found almost in the middle of the work piece. This occurs due to the least rigidity at the center along the length of the work piece. The obtained results are also compared with the literature. A good match was found between the results of the analytical model and published literature.
\end{abstract}

\section{Introduction}

Turning is a basic and an important metal cutting operation. The quality of the components produced by turning can be increased by reducing the errors caused during the process. Especially for long slender work pieces, reduction of diametral error leads to increased accuracy and higher part quality. This has attracted many researchers to evaluate the diameter error by experimental, numerical and analytical methods. Kalidasan et al. [1] determined the diameter error experimentally while double tool turning of cast iron with a coated carbide tool. It was observed that the diametral error reduced by $80 \%$ under certain cutting condition. Chen and Tian [2] predicted the dimensional error through a computerised compensation method. The trend of dimensional error was determined by least square polynomial fit. It was observed that the dimensional accuracy was significantly improved by the proposed method. Topal and Cogun [3] determined the diametral error

${ }^{*}$ Corresponding author: kalidasan.22180@lpu.co.in 
experimentally for various cutting conditions and different work piece diameter. An Artificial Neural Network (ANN) model was used to predict the error. Error correction was applied to the CNC part program. It was observed that the diametral error reduced by $90 \%$ by the proposed method. Karabulut [4] estimated the work piece deflection by Laser Distance Sensor (LDS). It was noted that the diametral error was maximum when the work piece deflection was maximum. It was concluded that the diametral error decreased with the increase in rigidity of the work piece. Use of follower rest is a common and widely used practice to increase the stiffness of the slender work piece. Jianliang and Rongdi [5] proposed a model to predict the diametral error considering cutting forces, cutting conditions and location of follower rest. It was revealed that the diametral error is mainly influence by the location of follower rest, depth of cut and feed rate. Phan et al. [6] conducted experimental studies on diametral errors in cantilever bar turning. Finite Element Analysis (FEA) was also performed to determine the work piece deflection. The part holder stiffness was taken into account along with shear deformation effect. The model was validated with the result of the experiments. Carrino et al. [7] developed a model to estimate the diameter error considering the deflections of cutting tool, work piece and work piece holder. Three types of work piece mounting were considered. Numerical examples was computed and validated with experimental results. The results provided some insight about error formation in turning. It can be seen from the literature that a lot of work has been done in predicting and estimating the diametral error during turning. But there was no model in which flexibility of both the end supports was taken into account. Realistic estimate of the machining accuracy can be obtained by considering head stock and tail stock supports to be flexible. Hence the primary aim of this research work is to evaluate the diameter error of slender work piece by considering flexible end supports. Further the analytical results are compared with the published literature.

\section{Analytical model}

The diametral error is caused primarily due to the work piece deflection, which in turn is mainly caused by the cutting forces, compliance of the machine tool, work piece and tool holder. In this study the radial component of the cutting force is considered. The formulation is based on Euler Bernoulli beam theory. Both the head stock and tail stock is considered as flexible support. The work piece is modelled as the propped cantilever beam supported between the headstock and tailstock. As propped cantilever beam is statically indeterminate, the reaction at the tailstock has been considered as redundant and other reactions are shown in terms of redundant reaction. Euler Bernoulli beam model for chuck centre mounting and the force model of turning process is shown in figure 1 (a) and (b).

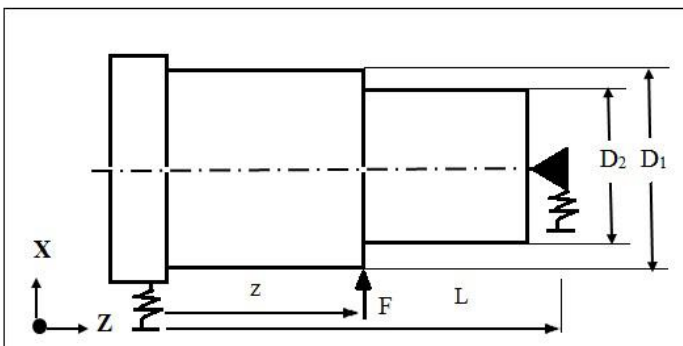

(a)

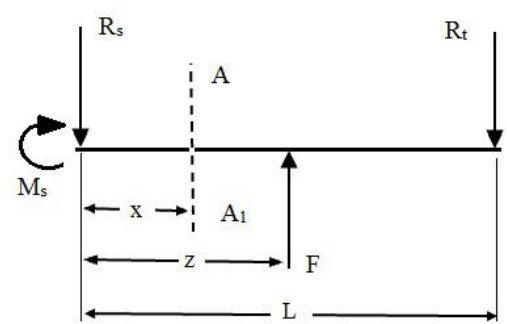

(b)

Fig. 1 (a). Euler Bernoulli beam model (b). Force model for turning process.

Taking the force and moment equilibrium and expressing the reaction force and reaction moment at the headstock in terms of cutting force and redundant reaction at the tailstock. 


$$
\begin{aligned}
& F=R_{s}+R_{t} \\
& M_{s}=F z-R_{t} L
\end{aligned}
$$

where $R_{s}$ and $M_{s}$ are the reaction and moment at head stock, $R_{t}$ is the reaction at the tail stock, $L$ is the work piece length, $F$ is the radial force component and $Z$ the distance between head stock and line of action of the radial force component. Considering section $A-A_{l}(0<\mathrm{x}<\mathrm{z})$ the moment equilibrium equation can be written as:

$$
v^{\prime \prime}=\left(1 / E I_{1}\right)\left(M_{s}-R_{s} x\right)
$$

where $x$ is the distance of section $A-A_{l}$ from the head stock. $I_{l}$ and $E$ are the initial moment of inertia along radial direction and elastic modulus of the work piece respectively. Substituting the values of $R_{S}$ and $M_{S}$ from Equation (1) and (2) in Equation (3)

$$
v^{\prime \prime}=\left(1 / E I_{1}\right)\left(F(z-x)-R_{t}(L-x)\right)
$$

Integrating the equilibrium Equation (4) the slope and the deflection are given by:

$$
\begin{aligned}
& v^{\prime}=C_{1}+\frac{x\left(-F(x-2 z)+(-2 L+x) R_{t}\right)}{2 E I_{1}} \\
& v=\frac{6 E x C_{1} I_{1}+6 E C_{2} I_{1}+x^{2}\left(-F(x-3 z)+(-3 L+x) R_{t}\right)}{6 E I_{1}}
\end{aligned}
$$

where $C_{1}$ and $C_{2}$ are the constants of integration. At $x=0, \quad v^{\prime}=0$ and $v=R_{s} C_{s}=\left(F-R_{t}\right) C_{s}$. Applying the boundary condition the values of constant of integration are obtained as: $C_{1}=0$ and $C_{2}=C_{s}\left(F-R_{t}\right)$

Substituting the values of constant in Equations (5) and (6) the equation of slope and deflection for section becomes

$$
\begin{gathered}
v^{\prime}=\frac{x\left(-F(x-2 z)+(-2 L+x) R_{t}\right)}{2 E I_{1}} \\
v=\frac{6 E C_{s} I_{1}\left(F-R_{t}\right)+x^{2}\left(-F(x-3 z)+(-3 L+x) R_{t}\right)}{6 E I_{1}}
\end{gathered}
$$

Now moving the section $A-A_{l}$ in-between $F$ and $R_{t}(\mathrm{z}<\mathrm{x}<\mathrm{L})$ the moment equilibrium equation is given as:

$$
v^{\prime \prime}=\left(1 / E I_{2}\right)\left(M_{s}-R_{s} x+F(x-z)\right)
$$

where $I_{2}$ is the moment of inertia of the work piece after turning. Substituting the values of $R_{S}$ and $M_{S}$ from Equations (1) and (2) in Equation (9)

$$
v^{\prime \prime}=\left(1 / E I_{2}\right)\left(-R_{t}(L-x)\right)
$$

Integrating the equilibrium Equation (10) the slope and the deflection are given by:

$$
\begin{gathered}
v^{\prime}=C_{3}+\frac{x(-2 L+x) R_{t}}{2 E I_{2}} \\
v=\frac{6 E x C_{3} I_{2}+6 \mathrm{EC}_{4} I_{2}+x^{2}(-3 L+x) R_{t}}{6 E I_{2}}
\end{gathered}
$$


where $C_{3}$ and $C_{4}$ are the constants of integration. At $x=z$ the deflection and slope of this section and prior section becomes equal. Equating Equations (7) and (11) for slope and Equations (8) and (12) for deflection. The values of constant are obtained as:

$$
\begin{gathered}
C_{3}=\frac{z\left(F z I_{2}+2 L I_{1} R_{t}-z I_{1} R_{t}-2 L I_{2} R_{t}+z I_{2} R_{t}\right)}{2 E I_{1} I_{2}} \\
C_{4}=\frac{1}{6 E I_{1} I_{2}}\left(-F z^{3} I_{2}+6 F E C_{s} I_{1} I_{2}-3 L z^{2} I_{1} R_{t}+2 z^{3} I_{1} R_{t}+3 L z^{2} I_{2} R_{t}-2 z^{3} I_{2} R_{t}-6 E C_{s} I_{1} I_{2} R_{r}\right)
\end{gathered}
$$

Substituting the values of constant in Equations (11) and (12) the slope and deflection equation is expressed as:

$$
\begin{gathered}
v^{\prime}=\frac{\left(-2 L x+x^{2}+2 L z-z^{2}\right) I_{1} R_{t}+z I_{2}\left(F z+(-2 L+z) R_{t}\right)}{2 E I_{1} I_{2}} \\
v=\frac{-(3 L-x-2 z)(x-z)^{2} I_{1} R_{t}+I_{2}\left(6 I C_{s} I_{1}\left(F-R_{t}\right)+z\left(F(3 x-z) z+\left(-6 L x+3 L z+3 x z-2 z^{2}\right) R_{t}\right)\right)}{6 \mathrm{EI}_{1} I_{2}}
\end{gathered}
$$

At $x=L$ the deflection is equal to $R_{t} C_{t}$, substituting the value of $x$ the expression of $R_{t}$ is given by:

$$
R_{t}=\frac{\left(3 F L z^{2}-F z^{3}+6 F E C_{s} I_{1}\right) I_{2}}{2\left(L^{3} I_{1}-3 L^{2} z I_{1}+3 L z^{2} I_{1}-z^{3} I_{1}+3 L^{2} z I_{2}-3 L z^{2} I_{2}+z^{3} I_{2}+3 E C_{s} I_{1} I_{2}+3 I C_{t} I_{1} I_{2}\right)}
$$

Now replacing $R_{t}$ in the Equation (16), and substituting $x=z$, the expression of deflection at cutting tool tip is obtained as:

$$
v=\frac{F\left(3(L-z)^{2} z^{4} I_{2}+12 E C_{s} I_{1}^{2}\left((L-z)^{3}+3 E C_{t} I_{2}\right)+4 z I_{1}\left(9 E(L-z)^{2} C_{s} I_{2}+z^{2}\left((L-z)^{3}+3 E C_{t} I_{2}\right)\right)\right)}{12 E I_{1}\left(z\left(3 L^{2}-3 L z+z^{2}\right) I_{2}+I_{1}\left((L-z)^{3}+3 E C_{s} I_{2}+3 E C_{t} I_{2}\right)\right)}
$$

It can be seen that the cutting tool edge deflection depends on the compliance of headstock and tailstock, distance of the cutting tool from the headstock, diameter, length and elastic modulus of work piece and cutting force. This cutting tool edge deflection gives rise to the diametral error of the work piece. The results of the developed model is compared with the literature in the subsequent section.

\section{Comparison of analytical model with literature}

Figure 2 shows the comparison of the results obtained from the analytical model with Kops et al. [8] The diametral error is evaluated through the radial deflection of the work piece for the different slenderness ratio of 4, 6, 7 and 8. It can seen that for the lowest slenderness ratio of 4 , the diametral error obtained was $26 \mu \mathrm{m}$. It occurs on the work piece at a distance of $140 \mathrm{~mm}$ from the head stock. It was observed that the variation between the present work and Kops et al. [8] is 7.7\%. Similarly for the slenderness ratio of 6, 7 the obtained diametral error was $32 \mu \mathrm{m}, 44 \mu \mathrm{m}$. In this case the ratio between the distance from head stock to the section $A-A_{I}$ and work piece length (x/L ratio) was found to be 0.47 and 0.57 respectively. On comparison with the above mentioned literature, the variation was found to be $6.2 \%$ and $9 \%$ respectively. For the highest slenderness ratio of 8 the diametral error obtained was $58 \mu \mathrm{m}$. It occurs at a distance of $170 \mathrm{~mm}$ from the head stock and the 
variation was $6.9 \%$. It is obvious that when the slenderness ratio increases the diametral error also increases. This is due to the decrease in rigidity of the work piece. Long back Murthy [9] put forth that form errors caused because of the machine tool rigidity is decreased by the work piece rigidity. Similarly the form errors caused by the work piece rigidity are decreased by machine tool rigidity.

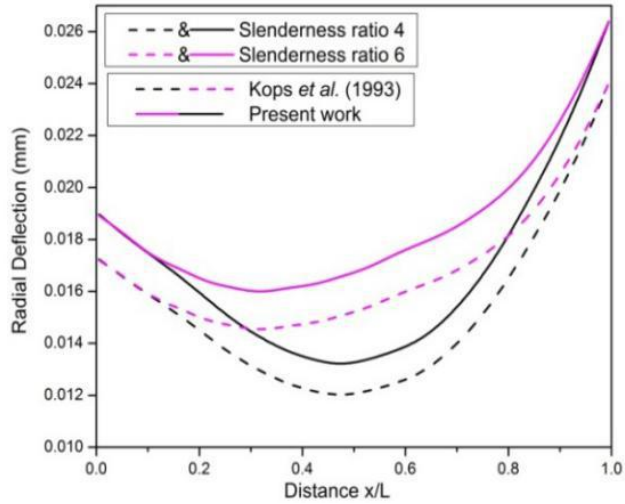

(a)

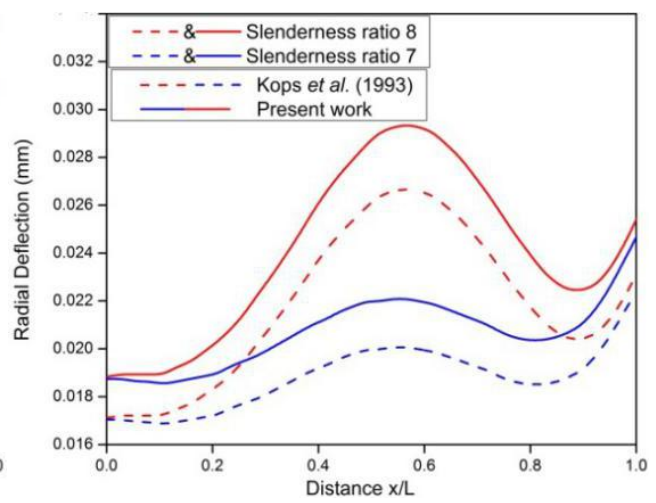

(b)

Fig. 2. Comparison of radial deflection of the work piece (a) For slenderness ratio 4 and 6 (b) For slenderness ratio 7 and 8 .

It can also be observed that the diametral error of the work piece is lesser at the head stock when compared with tail stock side. It is seen that for slenderness ratio of 4 and 6 the diametral error on the head stock is $37.6 \mu \mathrm{m}$ and on the tail stock side is $50.8 \mu \mathrm{m}$. Similarly for the slenderness ratio of 7 and 8 the diametral error on the head stock is $38 \mu \mathrm{m}$ whereas on the tail stock side it is $52.6 \mu \mathrm{m}$ and $52.8 \mu \mathrm{m}$ respectively. As the rigidity of the tail stock is lesser the diametral error of the work piece on the tail stock side is higher than the head stock side. Again on comparison with Kops et al.[8] the difference is $9 \%$ for both the head stock and tail stock side for the slenderness ratios of 4 and 6 . On similar lines for the slenderness ratio of 7 and 8 the deviation was $9.5 \%$ on the head stock side and $9 \%$ on the tail stock side. In overall all for all the values of slenderness ratio the diametral error of the work piece is less than $10 \%$ on comparison with the work of Kops et al.[8].

\section{Conclusions}

The proposed analytical model estimates the diameter error for various slenderness ratios of long work pieces. Further the results of the analytical model are compared with published literature. The following conclusions are arrived:

- The diameter error on the tail stock side is higher than the head stock side. This is attributed to the lesser rigidity of tailstock on comparison with the head stock. Diametral error of $52.8 \mu \mathrm{m}$ on the tailstock side and $38 \mu \mathrm{m}$ on the head stock side is obtained for the work piece with slenderness ratio 8 .

- The maximum diametral error was $58 \mu \mathrm{m}$ and it occurs at a distance of $170 \mathrm{~mm}$ from the head stock.

- The results of the proposed model agreed well with the published literature. The variation of diametral error is less than $10 \%$ on comparison with Kops et al. [8].

\section{References}


1. Kalidasan R Senthilvelan S Dixit U S and Vaibhav J 2016 Int. J. Precision Technology 6 142-158

2. Chen T and Tian X 2015 Int J Adv Manuf Technol 77 281-288

3. Topal E S and Cohan C 2011 J Intell Manuf 22 853-865

4. Karabulut A 2010 Metalurgija 49 57-60

5. Jianiang $\mathrm{G}$ and Rongdi H 2006 Int J Mach Tool Manu 46 1002-12

6. Phan A V Baron L Mayer J R R and Cloutier G 2003 Appl Math Model 27 221-232

7. Carrino L Giorleo G Polini W and Prisco U 2002 Int J Mach Tool Manu 42 1517-25

8. Kops L Gould M and Mizrach M 1993 J Eng Ind 115 253-257

9. Murthy R L 1969 Int J Mach Tool Des Res $10317-325$ 